\title{
Contribuição ao estudo de propriedades do solo-cimento autoadensável para fabricação de paredes monolíticas
}

\author{
Contribution to the study of properties of the self- \\ compacting soil-cement for construction of monolithic \\ walls
}

\section{Ana Paula da Silva Milani Christian Souza Barboza}

\section{Resumo \\ $\mathbf{F}$}

oram estudadas as propriedades físico-mecânicas do solo-cimento autoadensável (SCAA), de forma a desenvolver misturas de solo, cimento, água e aditivos para o alcance de desempenho mínimo para sua aplicação em fôrmas monolíticas sem a necessidade de compactação e adensamento mecânico. Para tal, pesquisou-se com as misturas de SCAA nos traços 1:8 e 1:12 (cimento:solo, em massa) a influência da relação água-solo, do teor e do tipo de aditivo, e adotou-se como consistência fluida adequada do SCAA o diâmetro de espalhamento de $250 \mathrm{~mm}$ no ensaio de determinação de índice de consistência de argamassas. Posteriormente, foram realizados os ensaios de compressão axial, compressão diametral, retração e fissuração para a análise do desempenho físico-mecânico. Os resultados mostraram que o SCAA alcança autoadensabilidade a partir do uso de aditivos superplastificantes na faixa de 0,8\% a 1,2\% em relação à massa de cimento, sendo os parâmetros de relevância para fabricação do SCAA e atendimento às solicitações usuais de paredes monolíticas a dosagem mínima de cimento na ordem de $8 \%$ em relação à massa de solo arenoso; e os Limites de Atterberg como referência para a relação água-solo mínima.

Palavras-chaves: Solo-cimento. Aditivo superplastificante. Consistência. Resistência mecânica. Retração. Fissuração.

\begin{abstract}
This study investigates the physical-mechanical properties of self-compacting soilcement (SCSC) in order to develop mixtures of soil, cement, water and additives to achieve its minimal performance for its application on monolithic walls without mechanical compaction and densification. The influence of the soil/water proportion, the percentage and the type of additives in SCSC mixtures in the ratios 1:8 and 1:12 (cement:soil, in mass) were investigated, and the SCSC fluid consistency adopted in the test to determine the consistency index of the mortar was a 250mm-scatter diameter. Subsequently, mechanical strength, shrinkage and cracking tests were undertaken to analyse physical-mechanical performance. The results showed that SCSC achieves self-compacting properties - through the use of superplasticizer additives - ranging from $0.8 \%$ to $1.2 \%$ in relation to the cement mass, with the relevant parameters for manufacturing SCSC that meets the usual demands on monolithic walls being a minimum cement dosage of $8 \%$ in relation to sandy soil mass; and the Atterberg Limits as a reference for the water/soil ratio.
\end{abstract}

Christian Souza B Dourados Dourados - MS - Brasil

Recebido em 11/11/14 Aceito em 12/04/16 Keywords: Soil-cement. Superplasticizers additives. Consistency. Mechanical strength.
Shrinkage. Cracking. 


\section{Introdução}

A construção civil busca, entre outros aspectos, solucionar problemas relacionados à otimização de recursos, bem como à diminuição de seus custos, sejam eles oriundos de sua extração, transporte ou aplicação. Para tanto, inúmeras soluções estão sendo estudadas em meio acadêmico e amplamente aplicadas, tais como os estudos desenvolvidos na área de gestão de suprimentos, inserção de maquinários nos canteiros de obras, utilização de sistemas pré-fabricados e a produção de edificações modulares e em série moldadas in loco.

Segundo Misurellie e Massuda (2009), a construção de edificações com paredes monolíticas de concreto possibilita com grande êxito a racionalização e o aumento de produtividade para edificações construídas em série, aferindo ao sistema de produção qualidade e economia de escala com relação à diminuição dos percentuais registrados para o déficit imobiliário brasileiro.

$\mathrm{Na}$ linha de pesquisa de materiais e técnicas construtivas não convencionais, pode ser destacada a utilização do solo como material construtivo. Esse material tende a apresentar-se como alternativa aos insumos utilizados em larga escala na construção civil. Atualmente, as pesquisas na área de solo estabilizado, para fins de vedação, estão direcionadas à produção de tijolos utilizando a técnica de prensagem ou mesmo a utilização da técnica de compactação do material para confecção de paredes monolíticas.

As paredes monolíticas de solo-cimento são fechamentos verticais formados por elemento único e contínuo da mistura das matérias-primas solo-cimento-água, podendo ser portante ou sem função estrutural. A técnica mais comum para preenchimento das paredes monolíticas de solocimento é a terra apiloada ou chamada taipa, a qual se baseia no solo-cimento compactado na umidade ótima, no próprio local, em camadas sucessivas, verticalmente, com o auxílio de fôrmas e guias. Para essa tecnologia construtiva tem-se a recomendação de construção de paredes monolíticas com espessura mínima de $10 \mathrm{~cm}$, o que proporciona rigidez e estabilidade ao conjunto. Porém, segundo Milani e Labaki (2008), ainda se encontram como usuais para os fechamentos monolíticos de solo-cimento espessuras de parede que variam entre $15 \mathrm{~cm}$ e $35 \mathrm{~cm}$ para o aproveitamento das propriedades térmicas da matéria-prima solo, como, por exemplo, a inércia térmica, ou mesmo para uso como estrutura portante da edificação.

Ressalta-se a normativa NBR 13553 (ABNT, 2012a), a qual especifica que na aplicação do solo- cimento compactado para a confecção de vedações verticais monolíticas a mistura de solo-cimentoágua deve apresentar resistência à compressão simples, aos 7 dias de idade, mínima de 1,0 MPa e capacidade de absorção de água igual ou inferior a $20 \%$.

Pesquisas acadêmicas apontam também a possibilidade de utilização do material solocimento no estado plástico, com consistência similar a uma argamassa, sendo empregado em fundações e revestimento de edificações. A utilização do solo-cimento plástico (SCP) permite maior rapidez na produção e aplicação do material, visto que o processo de preparação da mistura em betoneira proporciona maior agilidade e qualidade final, possibilitando a boa homogeneização dos elementos (SEGANTINI, 2000).

Sabe-se que as propriedades importantes dos compósitos de matriz cimentícia, seja no estado fresco, seja no estado endurecido, podem ser favoravelmente modificadas pelo uso de aditivos/adições. Diversos manuais e catálogos de fabricantes de aditivos químicos apresentam recomendações quanto à dosagem de aditivos para uso em argamassas e concretos, e, para os plastificantes, geralmente à base de lignossulfonatos, os percentuais ficam em torno de $0,30 \%$ a $0,50 \%$ com relação ao aglomerante. Os polifuncionais, podendo ser os de base de naftaleno, seriam dosados entre $0,40 \%$ e $1,0 \%$; e os superplastificantes, com destaque aos chamados de terceira geração, à base de policarboxilatos, ficariam dosados entre $0,60 \%$ e $2,0 \%$.

Miranda, Ângulo e Careli (2009), com o objetivo de se obterem misturas de solo-cimento plástico para a aplicação em obras de pequeno porte, estudaram três tipos de misturas (solo natural; solo $+20 \%$ de residuos de construção civil - RCD; e solo $+40 \%$ de RCD), variando-se a quantidade de cimento $(10 \%, 15 \%$ e $20 \%)$ em relação à massa da mistura e ainda acrescendo $2 \%$ de aditivo superplastificante referente à quantidade em massa de aglomerante. Na pesquisa, os referidos autores obtiveram resistências mecânicas na faixa de 3,5 MPa a 12,6 MPa aos 120 dias de idade, e o uso de aditivo possibilitou o alcance da trabalhabilidade adequada, com o abatimento do tronco de cone resultando em $100 \mathrm{~mm}$. Esse estudo também corroborou a potencialidade da aplicação do solocimento no estado plástico em estruturas simples e correntes de edificações, sem protensão, submetidas a sobrecargas máximas de $3 \mathrm{kN} / \mathrm{m}^{2}$, com vãos não excedendo 6 m. 
Milani e Barboza (2012) verificaram a possibilidade de fabricação de solo arenosocimento na consistência plástica, com o traço $1: 12$ (cimento:solo, em massa) com $0,65 \%$ de aditivo à base de lignossulfonato incorporado à mistura. Com a finalidade de aplicar-se a paredes monolíticas não portantes, os referidos autores obtiveram características aceitáveis, de acordo com as normas vigentes quanto a resistência mecânica, absorção de água e índice de vazios.

Ainda na linha das pesquisas com utilização de misturas de solo-cimento com maior fluidez, estudos atuais demonstram que existe a potencialidade da utilização do solo-cimento sem a necessidade de adensamento mecânico, possibilitando-se a utilização desse material de forma semelhante ao concreto autoadensável para preenchimento das paredes monolíticas, porém ainda são necessários estudos com maior profundidade nessa área.

Berté e Alcantara (2013) avaliaram 27 misturas de solo argiloso-cimento autoadensável em que se variaram as quantidades de cimento em $20 \%, 25 \%$ e $30 \%$ com relação ao solo, o percentual de teor de umidade entre elas, bem como os percentuais de aditivos superplastificantes. Os referidos autores avaliaram as resistências à compressão axial aos 28 dias e verificaram que a mistura com $20 \%$ de cimento, $42 \%$ de teor de umidade e $0,6 \%$ de aditivo superplastificante apresentou o menor valor, 2,01 $\mathrm{MPa}$. O maior valor verificado, 7,50 $\mathrm{MPa}$, foi obtido com a mistura contendo $30 \%$ de cimento, $36 \%$ de teor de umidade e $0,80 \%$ de aditivo superplastificante. Ainda segundo esses autores, as resistências para o solo-cimento autoadensável estão ligadas ao consumo de cimento e à relação agua-solo, pois com base nos resultados encontrados as misturas que tiveram maior teor de cimento incorporado tiveram maiores valores para a resistência mecânica; e entre essas misturas aquela que possuía menor relação agua-solo apresentou o melhor desempenho.

Dessa forma, estudar o comportamento das misturas de solo-cimento autoadensável com o objetivo de sua fabricação, lançamento e autoadensamento em painéis monolíticos não portantes se faz de suma importância para o desenvolvimento de tecnologias alternativas para a produção de elementos construtivos, e o uso de estabilizantes cimentantes e aditivos químicos pode atribuir características físico-mecânicas que satisfaçam os critérios de segurança, conforto e habitabilidade ao sistema construtivo, aprimorando, assim, a utilização do solo-cimento como vedação.

Este trabalho consistiu em estudar as propriedades físico-mecânicas do solo-cimento autoadensável (SCAA), de forma a desenvolver misturas de solo, cimento, água e aditivos para o alcance de desempenho mínimo para sua aplicação em fôrmas monolíticas sem a necessidade de compactação e adensamento mecânico.

\section{Materiais e métodos}

O solo utilizado nesta pesquisa foi oriundo de uma jazida da cidade de Campo Grande, MS, com características predominantes de solo arenoso. O solo foi seco ao ar, destorroado e peneirado na peneira de malha $4,8 \mathrm{~mm}$. Após caracterização física e determinação dos índices físicos, o solo arenoso foi classificado, segundo critérios da AASHTO, como A2-4, com composição granulométrica de $77 \%$ de areia, $23 \%$ de finos (argila + silte) e índice de plasticidade não plástico (NP). Esse solo apresentou características físicas adequadas para estabilização com cimento Portland, ou seja, $100 \%$ dos grãos do solo passando na peneira de malha $4,8 \mathrm{~mm}$, e $10 \%$ a $50 \%$ passando na peneira de malha $0,075 \mathrm{~mm}$, limite de liquidez menor ou igual a $45 \%$ e índice de plasticidade menor ou igual a $18 \%$. Dessa forma, optou-se pelo uso do cimento CPII E32.

Os aditivos superplastificantes utilizados tinham composição química diferente (fabricantes diferentes) com a mesma base química - éter policarboxilato, intitulado na pesquisa como aditivo PL e MG -, a fim de verificar a influência do teor e da composição específica dos aditivos. Essa base química foi adotada pelo potencial em proporcionar fluidez às misturas com grande presença de finos, já que os aditivos à base de naftaleno e de lignossulfonatos apresentam melhores resultados de redução de água, manutenção de coesão e trabalhabilidade nos compósitos cimentantes que apresentam areia grossa ou falta de coesão devido à falta de finos.

$\mathrm{Na}$ primeira etapa da pesquisa foi realizado o estudo de dosagem (Figura 1) para verificação do comportamento do solo-cimento com adição de aditivos superplastificantes, considerando a eficácia do aditivo em proporcionar a autoadensabilidade ao sistema solo-cimento, bem como o alcance dos critérios mínimos de desempenho físico-mecânico do solo-cimento autoadensável quando aplicado em paredes monolíticas. 
Figura 1 - Diagrama esquemático do programa experimental

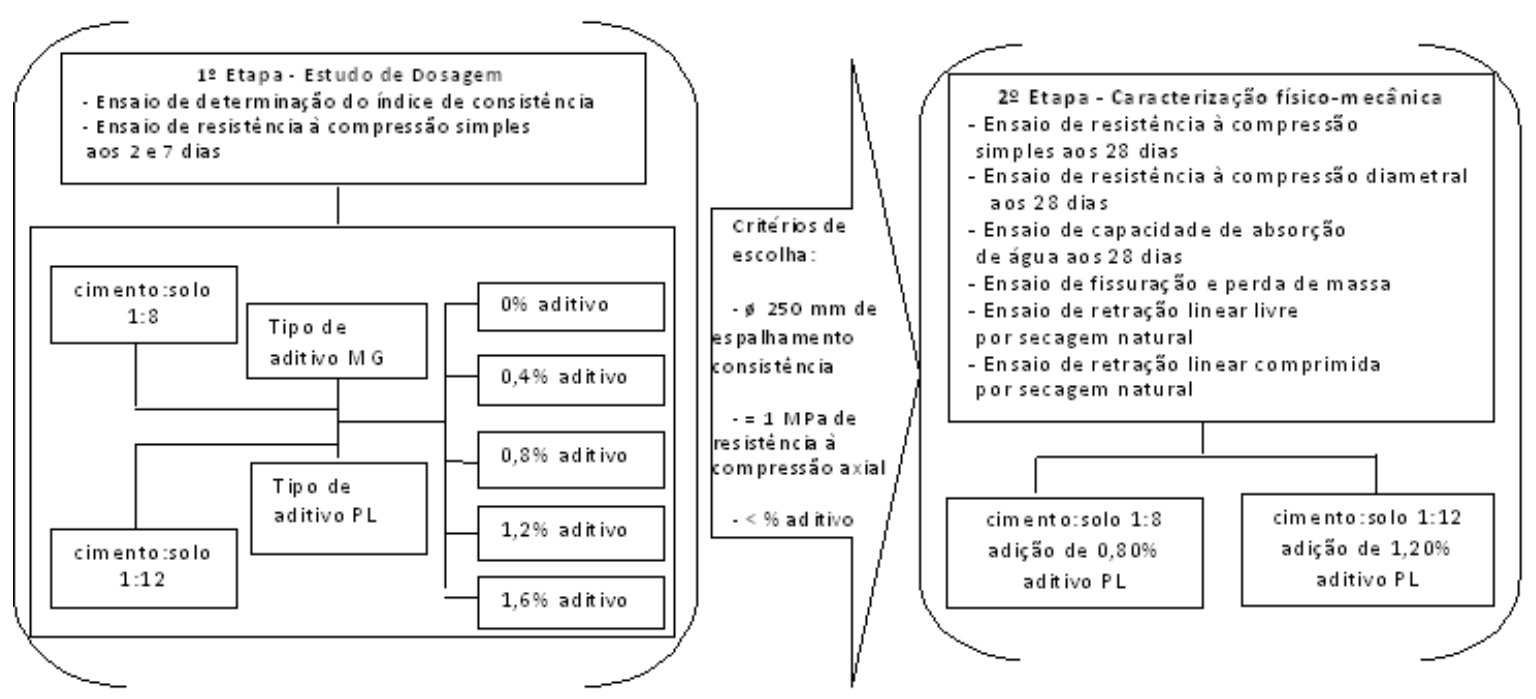

Para o estudo de dosagem do solo-cimento autoadensável, o solo e o índice de consistência foram fatores fixos; portanto, a dosagem se resumiu em variar a quantidade de aditivo de $0,4 \%$ a 1,6\% em relação à massa de cimento; o tipo de composição de aditivo à base de éter policarboxilato; e a adição de $8,3 \%$ e $12,5 \%$ de cimento para estabilização do solo, os quais foram representados pelos traços 1:12 e 1:8 (cimento:solo, em massa) respectivamente. Este estudo foi adotado a partir da adaptação do procedimento de dosagem de concreto autoadensável prescrito por Tokudome (2006), o qual propõe fixar as quantidades de agregados variando-se a relação água-aglomerante e a quantidade de aditivo, sendo fator preponderante a trabalhabilidade para o resultado final do traço do concreto autoadensável.

Também se variou a quantidade de água adicionada às misturas, gerando relações de águasolo em conformidade com o alcance do índice de consistência estipulado por Edamatsu, Nishida e Ouchi (1999), que consideram que argamassas para concreto autoadensável devem apresentar diâmetro de espalhamento na faixa de $200 \mathrm{~mm}$ a $280 \mathrm{~mm}$ no ensaio de determinação de índice de consistência de argamassas cimentícias. Assim, adotou-se para os tratamentos de SCAA diâmetro médio de abertura de espalhamento próximo a 250 $\mathrm{mm}$ durante a determinação do índice de consistência adaptado da NBR 13276 (ABNT, 2005).

Alcançada a consistência fluida com abertura de espalhamento de $250 \mathrm{~mm}$ do SCAA (Figura 2), foi seguido o processo descrito na NBR 5738 (ABNT, 1994), moldando corpos de prova cilíndricos com dimensão de $\varnothing 100 \times 200 \mathrm{~mm}$, sem adensamento com haste, e após $48 \mathrm{~h}$ foram desmoldados e levados para câmara úmida para posterior realização do ensaio de resistência à compressão axial nas idades de 2 e 7 dias, conforme disposto na NBR 12025 (ABNT, 2012).

Para a segunda etapa, foram escolhidos os tratamentos de SCAA que obtiveram limites mínimos de resistência à compressão simples exigidos pela NBR 13553 (ABNT, 2012a), com o menor teor de aditivo superplastificante (Figura 2). Seguiu-se a aplicação dos ensaios para caracterização físico-mecânica específica do SCAA em maiores idades, assim averiguando a potencialidade de uso como material de construção em paredes monolíticas, bem como o comportamento das fissuras e retrações quanto a velocidade, formato, dimensões, quantidade e significância no desempenho do sistema.

De forma análoga, foram confeccionados 12 corpos de prova cilíndricos para cada tratamento de SCAA e aplicados os seguintes ensaios: resistência à compressão simples e à compressão diametral, e capacidade de absorção de água, conforme, respectivamente, as normas NBR 12025 (ABNT, 2012b), NBR 7222 (ABNT, 2011) e NBR 13555 (ABNT, 2012c), aos 28 dias de idade.

Para a complementação dessa caracterização físico-mecânica, foram realizados os ensaios de fissuração e perda de massa utilizando diretrizes adaptadas da norma ASTM C1579 (AMERICAN..., 2006), sendo realizada a indução de fissuras por meio de restrições no molde do corpo de prova (Figura 3a) e controladas as condições de temperatura, umidade relativa e velocidade de vento pelos equipamentos sensor tipo Data Logger e anemômetro. 
Já o ensaio de retração linear livre por secagem natural seguiu as descrições Wongtanakitcharoen e Naaman (2007), no qual foram acoplados extensômetros nos corpos de prova cilíndricos com dimensão de $\varnothing 100 \times 200 \mathrm{~mm}$ para aferir os deslocamentos nas primeiras $24 \mathrm{~h}$ após a moldagem até a idade de 7 dias; e para o ensaio de retração linear comprimida por secagem natural foi verificado o efeito de uma carga constante de 0,06 $\mathrm{kg} / \mathrm{cm}^{2}$ (Figura $3 \mathrm{~b}$ ).

\section{Resultados e discussão \\ Primeira etapa: estudo de dosagem do SCAA}

Os resultados preliminares do estudo de dosagem do SCAA estão demonstrados na Figura 4, na qual se verificou a relação água-solo inicial de 0,23; e ainda se relacionaram os teores de aditivos de $0,0 \%, 0,4 \%, 0,8 \%, 1,2 \%$ e $1,6 \%$ incorporados aos traços 1:8:MG, 1:8:PL, 1:12:MG e 1:12:PL (cimento:solo: \% de aditivo) com seus correspondentes diâmetros de aberturas de espalhamento (índice de consistência).

Figura 2 - Aspecto do SCAA no ensaio de determinação do índice de consistência
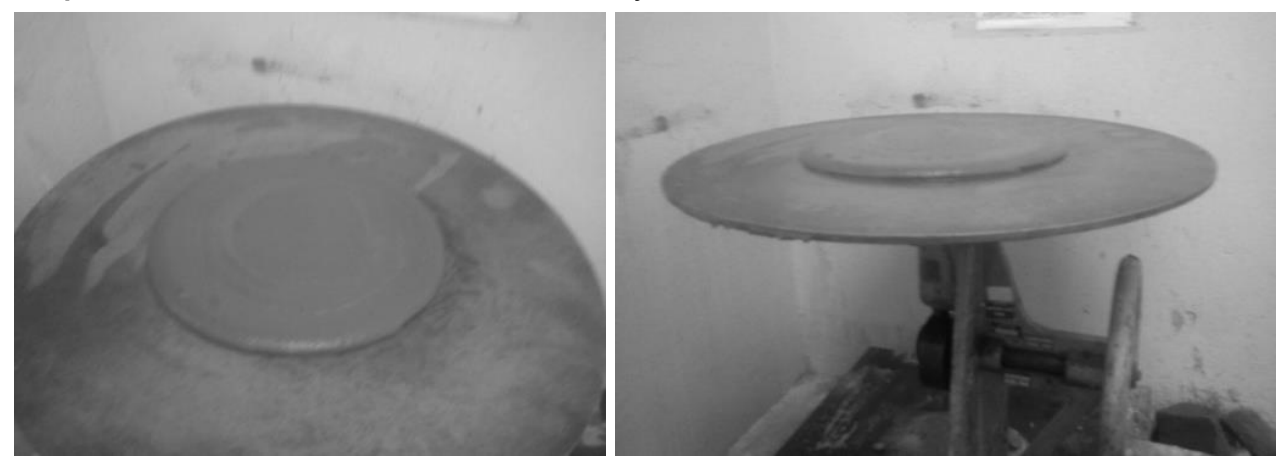

Figura 3 - (a) Ensaio de avaliação da fissuração e perda de água; e (b) Ensaio de avaliação das retrações linear livre e comprimida por meio de secagem natural

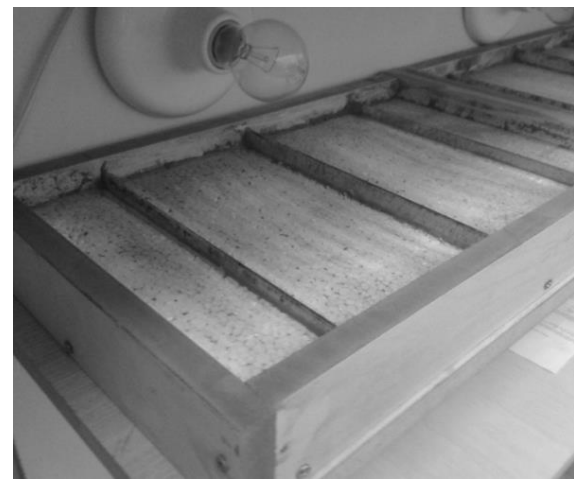

(a)

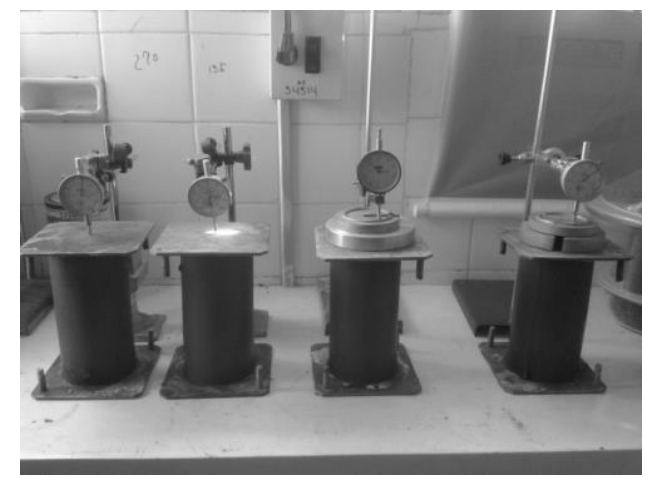

(b) 
Figura 4 - Relação entre teor de aditivo e abertura de espalhamento (índice de consistência) com relação água-solo de 0,23

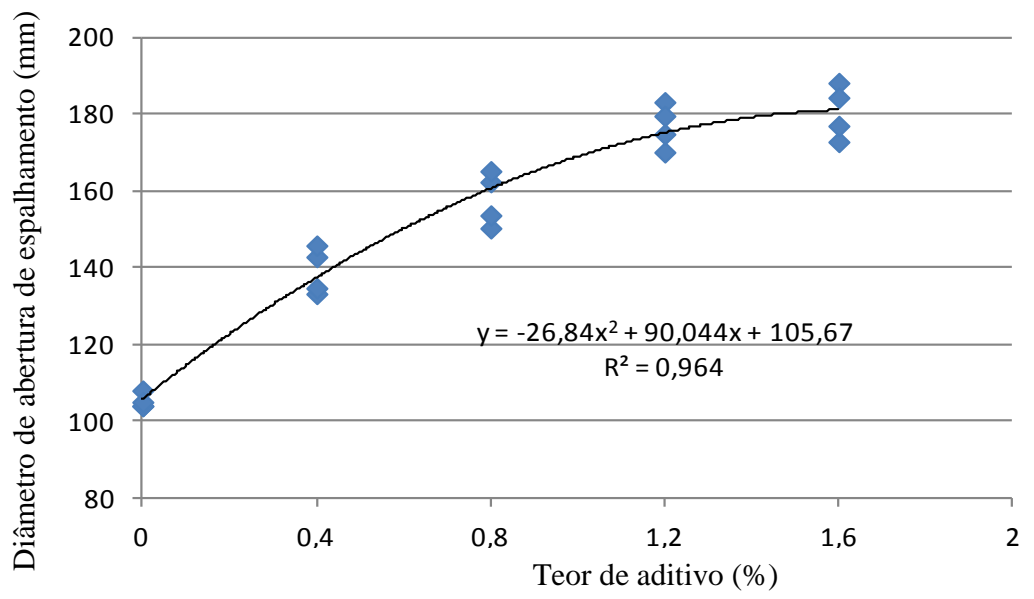

Conforme se observa na Figura 4, a quantidade de água adicionada à mistura solo-cimento foi insuficiente para se alcançar o parâmetro de mistura fluida com $250 \pm 20 \mathrm{~mm}$ de abertura de diâmetro, ou seja, partindo-se da relação água-solo de 0,23 , a qual confere consistência plástica ao SCAA e adicionando-se aditivos superplastificantes, independentemente do tipo de composição e da quantidade de água presente na formulação do aditivo, o solo ainda necessita de aumento do teor de água para atingir a autoadensabilidade. Também se observou que há aumento significativo no espalhamento da mistura nos intervalos dos teores de aditivos de $0,4 \%$ a $0,8 \%$ e de $0,8 \%$ a $1,2 \%$, sendo não significativo quando adicionados aditivos no intervalo entre $1,2 \%$ e $1,6 \%$.

Assim, o estudo inicial de dosagem de aditivo mostrou que, independentemente da composição do aditivo à base de policarboxilatos e da quantidade de cimento para estabilização do solo (existência de correlação com $\mathrm{R}^{2} \approx 1$ ), para a obtenção de ganhos significativos na consistência fluida de solos arenosos deve-se trabalhar com adição de teores de aditivos em torno de $0,80 \%$ a $1,20 \%$ em relação à massa de cimento, partindo-se do teor de água a ser incorporado ao SCAA de no mínimo 20\% (teor de água em relação à massa do solo-cimento), o que está em conformidade com a teoria de plasticidade de Casagrande, em que o teor de umidade mínimo para solos pouco e sem plasticidade está no valor de alcance de limite de liquidez para solos caracterizados como arenosos.

Segundo Hartmann (2002), os compostos éter policarboxilato possuem a propriedade de repulsão estérica, ou seja, possuem moléculas com cadeias longas e ramificadas, formando uma barreira física que dificulta a aglomeração das partículas cimentantes, e quanto maiores são essas cadeias, maiores serão as propriedades fluidificantes. No entanto, mesmo que o aditivo superplastificante diminua a água com relação aos processos de hidratação e floculação dos compostos cimentantes, para a ocorrência de cisalhamento entre as partículas de solo tem-se o limite mínimo de água necessário para a fluidificação dos siltes e das argilas; e esse limite encontra-se dentro dos conceitos de limite de liquidez do solo (LL), sendo o LL a água necessária para que o material fino do solo arenoso se comporte como líquido viscoso. Portanto, a redução de água dentro do sistema solo-cimento autoadensável será limitada pela quantidade de finos presentes no solo, ou seja, pelo limite de liquidez do solo.

Com relação à classificação qualitativa do SCAA, no estado fresco, durante a aplicação do ensaio de determinação de índice de consistência adaptado para SCAA, pode-se observar que o uso de aditivos químicos à base de éter policarboxilato melhorou as características de homogeneidade e a resistência à segregação, visto que as misturas referenciais de solo-cimento sem aditivo apresentaram forte exsudação, fato devido principalmente à quantidade excessiva de água que necessitou ser adicionada para que elas apresentassem a consistência fluida preestabelecida, resultando na impossibilidade de sua aplicação.

Ilustra-se na Figura 5 que a incorporação de aditivos superplastificantes nas misturas de solocimento reduziu significativamente a relação águasolo para a obtenção da consistência fluida, e quanto maior o teor de aditivo e a dosagem de cimento, maiores foram as reduções de água para 
resultar em um sistema solo-cimento-aditivo fluido. No entanto, não houve redução do teor de água abaixo do limite de liquidez característico do solo arenoso $(\mathrm{LL}=20 \%)$, demonstrando que o alcance do autoadensamento do sistema solocimento está intimamente ligado aos limites de consistência do solo - Limites de Atterberg.
A partir dos resultados de índice de consistência dos tratamentos de SCAA, foram realizados os ensaios de resistência mecânica, cujos resultados estão apresentados na Tabela 1. Nesta fase não foram avaliados os traços referência (solo-cimento sem aditivo), pois estes não atenderam aos critérios mínimos estabelecidos para o SCAA no estado fresco.

Figura 5 - Relação entre teor de água e teor de cimento em função do teor de aditivo

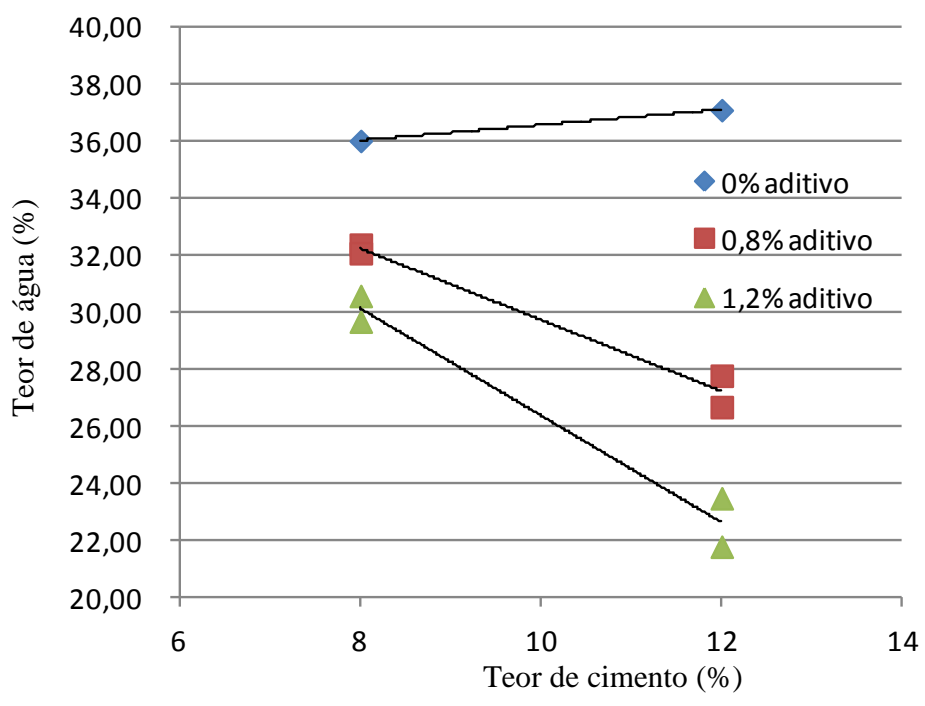

Tabela 1 - Valores de resistência à compressão simples dos tratamentos de SCAA

\begin{tabular}{|c|c|c|c|}
\hline $\begin{array}{c}\text { Traço SCAA } \\
\text { cimento:solo - teor de } \\
\text { aditivo (tipo) } \\
\end{array}$ & $\begin{array}{l}\text { Tensão média } \\
\text { (MPa) } \\
2 \text { dias } \\
\end{array}$ & $\begin{array}{l}\text { Tensão média } \\
\text { (MPa) } \\
7 \text { dias } \\
\end{array}$ & $\begin{array}{c}\text { Teor de água } \\
\text { adicionado ao solo- } \\
\text { cimento }(\%) * *\end{array}$ \\
\hline SCAA1:8-0,80\%(MG) & $\begin{array}{c}0,54 \mathrm{~d} \\
\pm 0,04(8,36)^{*}\end{array}$ & $\begin{array}{c}1,05 \mathrm{~d} \\
\pm 0,07(6,67) \\
\end{array}$ & $27,79 \%$ \\
\hline SCAA1:8-1,20\%(MG) & $\begin{array}{c}0,62 \mathrm{c} \\
\pm 0,01(1,02)\end{array}$ & $\begin{array}{c}1,26 \mathrm{c} \\
\pm 0,08(6,33)\end{array}$ & $21,83 \%$ \\
\hline SCAA $1: 8-0,80 \%(\mathrm{PL})$ & $\begin{array}{c}0,73 \mathrm{~b} \\
\pm 0,03(4,61)\end{array}$ & $\begin{array}{c}1,46 \mathrm{~b} \\
\pm 0,08(5,45)\end{array}$ & $26,74 \%$ \\
\hline SCAA $1: 8-1,20 \%(\mathrm{PL})$ & $\begin{array}{c}1,08 \mathrm{a} \\
\pm 0,04(3,40)\end{array}$ & $\begin{array}{c}1,79 a \\
\pm 0,08(4,72)\end{array}$ & $23,51 \%$ \\
\hline SCAA1:12-0,80\%(MG) & $\begin{array}{c}0,09 \mathrm{~g} \\
\pm 0,01(8,43)\end{array}$ & $\begin{array}{c}0,68 \mathrm{e} \\
\pm 0,02(3,54)\end{array}$ & $32,44 \%$ \\
\hline SCAA1:12-1,20\%(MG) & $\begin{array}{c}0,19 \mathrm{f} \\
\pm 0,02(10,67)\end{array}$ & $\begin{array}{c}0,69 \mathrm{e} \\
\pm 0,05(7,15) \\
\end{array}$ & $30,56 \%$ \\
\hline SCAA1:12-0,80\%(PL) & $\begin{array}{c}0,22 \text { ef } \\
\pm 0,03(11,47) \\
\end{array}$ & $\begin{array}{c}0,82 \mathrm{e} \\
\pm 0,09(10,68)\end{array}$ & $32,08 \%$ \\
\hline SCAA1:12-1,20\%(PL) & $\begin{array}{c}0,29 \mathrm{e} \\
\pm 0,03(9,71) \\
\end{array}$ & $\begin{array}{c}1,21 \mathrm{c} \\
\pm 0,01(0,73) \\
\end{array}$ & $29,73 \%$ \\
\hline
\end{tabular}

Nota: * \pm desvio padrão (coeficiente de variação \%); para comparação entre traços diferentes, em cada coluna, médias seguidas da mesma letra minúscula não diferem entre si pelo teste de Tukey $(\mathrm{p}<0,05)$. Válido; ${ }^{* *}$ teor de água adicionado ao solo-cimento para o alcance do $\varnothing 250 \mathrm{~mm}$ de espalhamento (índice de consistência). 
Na Tabela 1 notou-se diferença significativa nos valores de resistência à compressão simples das misturas de solo-cimento com $0,8 \%$ e $1,2 \%$ de aditivo, e com o aumento do teor de aditivo e do teor de cimento, aumentaram as resistências mecânicas, fato esse que corrobora o menor consumo de água pelas misturas aditivadas com teor de $1,2 \%$ e estabilizadas com $12,5 \%$ de cimento. Também se observou que, apesar de os dois tipos de aditivos proporcionarem fluidez ao SCAA, a diversificação nas formulações químicas dos aditivos à base de éter policarboxilato de diferentes fabricantes influenciou no desempenho mecânico das misturas de solo-cimento, visto que houve a necessidade do aumento do teor de água para obter a mesma consistência fluida e, consequentemente, a diminuição da resistência mecânica.

Como esperado, todas as misturas de solo-cimento autoadensáveis aumentaram significativamente sua resistência mecânica no decorrer de 7 dias de idade, sendo que os tratamentos que consumiram água no teor maior que $30 \%$ não alcançaram a resistência à compressão axial mínima de $1 \mathrm{MPa}$, exigida pela NBR 13553 (ABNT, 2012a) para o material solo-cimento aplicado em paredes monolíticas de vedação.

A caracterização mecânica dos tratamentos de SCAA mostrou que o aumento do teor do estabilizante cimento aumentou significativamente a resistência mecânica do material solo-cimento, levando a considerar que o teor mínimo de $8,3 \%$ de cimento (em massa) seja adicionado aos solos arenosos para que as características físicomecânicas estejam adequadas para aplicação como material autoadensável.

\section{Segunda etapa: caracterização físico-mecânica do SCAA}

Os valores apresentados na Tabela 2 conferem ao SCAA potencialidade de aplicação como material para o sistema de paredes monolíticas, sendo importante destacar que a perda de fluidez foi considerada pelo fato de a abertura de espalhamento do SCAA apresentar-se com diâmetro menor que $200 \mathrm{~mm}$. Também se destaca que os corpos de prova de SCAA apresentaram condições físicas mínimas para a desforma a partir de 2 dias de cura, fato esse confirmado com os valores iniciais de resistência à compressão simples aos 2 dias de idade, o que sugere o período mínimo de secagem para retirada de fôrmas quando aplicado como material de preenchimento de paredes monolíticas. Outro ponto a ser melhorado é o tempo de perda de fluidez, sendo sugerida a adição de aditivos plastificantes momentos antes do descarregamento do SCAA para o aumento do tempo de trabalhabilidade.

O estudo das retrações durante o estágio de endurecimento do sistema solo-cimento autoadensável foi monitorado durante as primeiras 48 h (fase plástica do SCAA), sendo observada menor intensidade das retrações livres em relação às retrações comprimidas. Tal fato já era esperado, pois a carga constante que foi aplicada às misturas em suas idades iniciais provocou diferenças de pressões, aumentando ainda mais as forças hidrostáticas no sistema. Essas tensões capilares formam meniscos, que exercem tensões no esqueleto do material cimentício, causando as retrações (Figura 6). Também se notou que o surgimento e a velocidade das retrações são mais intensos no primeiro dia devido à perda de água por evaporação (secagem natural), verificando-se para o sistema SCAA tendência de estabilização após 2 dias de idade.

Ainda na Figura 6, ao se analisar o formato das curvas, verifica-se a semelhança do comportamento delas, e os valores finais encontrados para as retrações máximas e mínimas $(0,74 \mathrm{~mm}$ a $1,74 \mathrm{~mm})$ por Bahar, Benazzoug e Kenai (2004) para as diferentes dosagens de solocimento compactado são da mesma ordem de grandeza do estudo de retrações para o SCAA $(1,05 \mathrm{~mm}$ a $1,55 \mathrm{~mm})$.

Tabela 2 - Resultados da caracterização físico-mecânica do SCAA aos 28 dias de idade

\begin{tabular}{|c|c|c|c|c|c|c|c|c|}
\hline $\begin{array}{c}\text { Traço SCAA } \\
\text { cimento:solo - } \\
\text { teor de aditivo } \\
\text { (tipo) }\end{array}$ & $\begin{array}{l}\text { Compressão } \\
\text { axial (MPa) }\end{array}$ & $\begin{array}{c}\text { Compressão } \\
\text { diametral } \\
(\mathrm{MPa})\end{array}$ & $\begin{array}{l}\text { Absorção de } \\
\text { água (\%) }\end{array}$ & $\begin{array}{l}\text { Massa esp. } \\
\text { aparente no } \\
\text { estado } \\
\text { endurecido } \\
\left(\mathrm{g} / \mathrm{cm}^{3}\right)\end{array}$ & $\begin{array}{c}\text { Teor de } \\
\text { água } \\
\text { adicionado } \\
\text { SCAA (\%) }\end{array}$ & $\begin{array}{c}\text { Relação } \\
\text { Água- } \\
\text { cimento }\end{array}$ & $\begin{array}{l}\text { Relação } \\
\text { água- } \\
\text { solo }\end{array}$ & $\begin{array}{c}\text { Perda } \\
\text { de } \\
\text { fluidez } \\
\text { (min) }\end{array}$ \\
\hline $\begin{array}{l}\text { SCAA1:8- } \\
0,80 \%(\mathrm{PL})\end{array}$ & $\begin{array}{c}1,72 \mathrm{a} \\
\pm 0,04(2,12)\end{array}$ & $\begin{array}{c}0,43 \mathrm{a} \\
\pm 0,03(7,57)\end{array}$ & $\begin{array}{c}18,84 \mathrm{a} \\
\pm 0,42(2,23)\end{array}$ & 1,87 & 25,45 & 2,12 & 0,33 & 23 \\
\hline $\begin{array}{c}\text { SCAA1:12- } \\
1,20 \%(\text { PL) }\end{array}$ & $\begin{array}{c}1,60 \mathrm{~b} \\
\pm 0,05(3,35)\end{array}$ & $\begin{array}{c}0,40 \mathrm{a} \\
\pm 0,09(21,74)\end{array}$ & $\begin{array}{c}19,76 \mathrm{a} \\
\pm 1,34(6,78)\end{array}$ & 1,84 & 30,69 & 3,52 & 0,35 & 17 \\
\hline
\end{tabular}

Nota: * \pm desvio padrão (coeficiente de variação \%); e para comparação entre traços diferentes, em cada coluna, médias seguidas da mesma letra minúscula não diferem entre si pelo teste de Tukey $(p<0,05)$. 
Figura 6 - Evolução das retrações lineares ao longo do tempo do SCAA por secagem natural

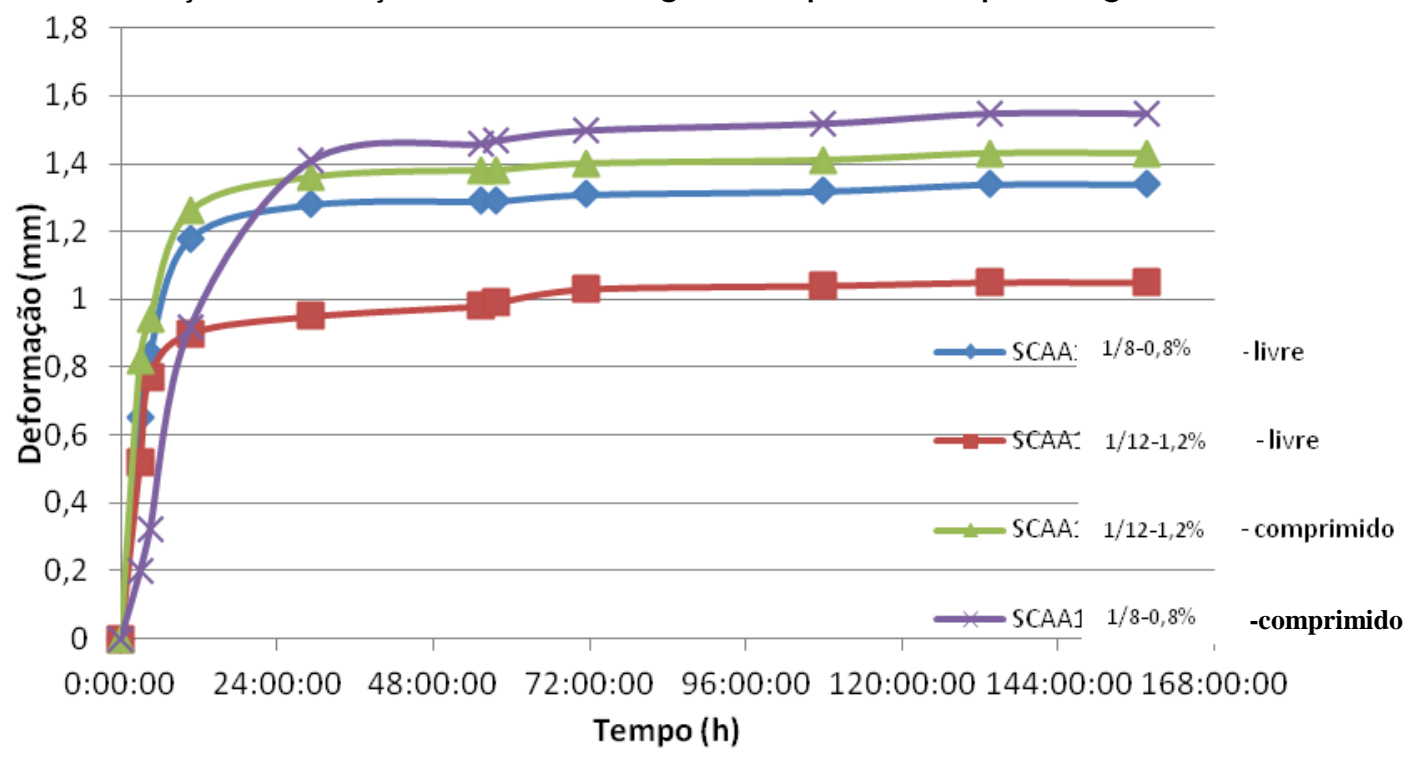

Tabela 3 - Resultados do ensaio de fissuração e perda de massa*

\begin{tabular}{c|c|c|c|c|c}
\hline $\begin{array}{c}\text { Traço SCAA } \\
\text { cimento:solo - } \\
\text { teor de aditivo } \\
\text { (tipo) }\end{array}$ & $\begin{array}{c}\text { Máxima } \\
\text { retração } \\
\text { livre } \\
(\mathbf{m m} / \mathbf{m})\end{array}$ & $\begin{array}{c}\text { Área total das } \\
\text { fissuras } \\
\text { expostas ao } \\
\text { calor e vento } \\
\left(\mathbf{m m}^{2}\right)\end{array}$ & $\begin{array}{c}\text { Área total } \\
\text { das fissuras } \\
\text { exposta ao } \\
\text { vento }\left(\mathbf{m m}^{2}\right)\end{array}$ & $\begin{array}{c}\text { Perda de } \\
\text { massa relativa } \\
\text { exposta ao } \\
\text { calor e vento } \\
\left(\mathbf{g} / \mathbf{m}^{2} \mathbf{h}\right)\end{array}$ & $\begin{array}{c}\text { Perda de massa } \\
\text { relativa exposta } \\
\text { ao vento } \\
\left(\mathbf{g} / \mathbf{m}^{2} \mathbf{h}\right)\end{array}$ \\
\hline $\begin{array}{c}\text { SCAA1:8- } \\
0,80 \%(\mathrm{PL})\end{array}$ & 5,25 & $1.028,48$ & 443,65 & 528 & 397 \\
\hline $\begin{array}{c}\text { SCAA1:12-1,20\% } \\
\text { (PL) }\end{array}$ & 7,75 & 859,48 & 293,95 & 1323 & 1080 \\
\hline
\end{tabular}

Nota: *ensaio adaptado da norma ASTM C1579 (2006).

No ensaio de retração proposto pelo Ceped (CENTRO..., 1984), o solo deve ser misturado com água até alcançar consistência plástica e deve ser adensado manualmente em uma fôrma retangular, com medidas $60,0 \times 8,5 \times 3,5 \mathrm{~cm}^{3}$. Após 7 dias de repouso à sombra, procede-se nesse solo à leitura da retração no sentido do comprimento da caixa. De acordo com o Ceped (CENTRO..., 1984), para ser viável o uso de determinado solo para a confecção de solo-cimento, a soma das fissuras existentes entre as paredes da fôrma e a amostra de solo deve ser inferior a $20 \mathrm{~mm}$ e a amostra não deve apresentar trinca transversal. No SCAA, os maiores valores verificados para as retrações foram aproximadamente 3 vezes menores que esse limite.

No entanto, ao se aplicarem critérios de classificação de argamassas cimentícias quanto à fissuração proposta por CSTB (CENTRE..., 1982), a qual se baseia no princípio de que a tendência à fissuração aumenta com o aumento da retração de secagem, verificou-se alta suscetibilidade a fissuração do SCAA, ou seja, retrações iguais ou maiores que $1,20 \mathrm{~mm} / \mathrm{m}$. Essa previsão corroborou-se diante do ensaio de fissuração e perda de massa das misturas de SCAA quando expostas a fontes de calor e vento (Tabela 3 ), destacando-se que o SCAA com maior teor de água incorporado obteve maior perda de massa relativa por hora e que o SCAA com maior teor de cimento apresentou maior área de fissuração, devido a maior presença de finos.

Os métodos de avaliação da retração e fissuração aplicados ao SCAA devem levar em consideração o sistema construtivo e as condições de aplicação e uso. Quando ocorre a análise da retração a partir dos ensaios propostos pelo Ceped, considera-se que no SCAA será aplicado algum tipo de adensamento, prensagem ou compactação; e tais técnicas, além de diminuírem a tendência de ocorrer fissuração no produto final, não representam o processo construtivo de SCAA. No entanto, ao se analisar a fissuração das misturas de SCAA por meio do método CSTB, tal sistemática pode ser considerada rígida, pois é aplicada às argamassas, que, de maneira geral, possuem 
pequenas espessuras e grandes áreas expostas à evaporação quando aplicadas, sendo assim exigidos da argamassa valores quanto à fissuração e retração próximo a zero. Essas observações trazem a necessidade de estudos em relação ao desenvolvimento de critérios e de processo mais adequado de avaliação da fissuração do material SCAA.

\section{Contribuições}

Com o advento da tecnologia dos aditivos químicos à base de éter policarboxilato foi possível a obtenção do sistema solo-cimento autoadensável (SCAA) com potencialidade de aplicação como material de execução de paredes monolíticas, sendo alcançadas pelo SCAA, na dosagem de 1:8 (cimento:solo, em massa) com 0,8\% aditivo e relação água-cimento igual a 2 , a média de resistência à compressão simples de $1,72 \mathrm{MPa}$ e a capacidade de absorção de água máxima de $18 \%$. Os parâmetros de relevância para fabricação do SCAA são a adição de superplastificantes na faixa de $0,8 \%$ a $1,2 \%$ em relação à massa de cimento e a dosagem mínima de estabilizante cimentante na ordem de $8 \%$ em relação à massa de solo arenoso. $\mathrm{O}$ aditivo químico superplastificante exerce importante papel para a estabilidade do SCAA no estado fresco, conferindo às misturas redução de água, aumento da mobilidade e não ocorrência de segregação dos componentes. No entanto, deve-se levar em consideração a importância da relação água-solo tanto para o alcance da fluidez do solocimento como para características físico-mecânicas mínimas de aplicação como material de construção, visto que a redução de água de amassamento dentro do sistema SCAA terá como referência os limites de consistência do solo (Limites de Atterberg). Também se ressalta que o SCAA durante o processo de endurecimento apresenta retrações e suscetibilidade à ocorrência de fissurações para aplicação em paredes monolíticas, assim necessitando de estudos para proposição de melhorias nos quesitos desempenho e durabilidade.

\section{Referências}

\author{
AMERICAN SOCIETY FOR TESTING AND \\ MATERIALS. ASTM C-1579: standard test \\ method for evaluating plastic shrinkage cracking \\ of restrained fiber reinforced concrete (using a \\ steel form insert). Philadelphia, 2006.
}

ASSOCIAÇÃO BRASILEIRA DE NORMAS TÉCNICAS. NBR 5738: moldagem e cura de corpos-de-prova cilíndricos ou prismáticos de concreto. Rio de Janeiro, 1994.
ASSOCIAÇÃO BRASILEIRA DE NORMAS TÉCNICAS. NBR 7222: concreto e argamassa: determinação da resistência à tração por compressão diametral de corpos de prova cilíndricos. Rio de Janeiro, 2011.

ASSOCIAÇÃO BRASILEIRA DE NORMAS TÉCNICAS. NBR 12025: solo-cimento: ensaio de compressão simples de corpos-de-prova cilíndricos: método de ensaio. Rio de Janeiro, 2012b.

\section{ASSOCIAÇÃO BRASILEIRA DE NORMAS}

TÉCNICAS. NBR 13276: argamassa para assentamento e revestimento de paredes e tetos: preparo da mistura e determinação de índice de consistência. Rio de Janeiro, 2005.

ASSOCIAÇÃO BRASILEIRA DE NORMAS TÉCNICAS. NBR 13553: materiais para emprego em parede monolítica de solo-cimento sem função estrutural: requisitos. Rio de Janeiro, 2012a.

\section{ASSOCIAÇÃO BRASILEIRA DE NORMAS TÉCNICAS. NBR 13555: solo-cimento: determinação da absorção de água: método de ensaio. Rio de Janeiro, 2012c.}

BAHAR, R.; BENAZZOUG M.; KENAI, S. Performance of Compacted Cement-Stabilised Soil. Cement \& Concrete Composites, v. 26, n. 7, p. 811-20, 2004.

BERTÉ, S. D. D.; ALCANTARA, M. A. M. Estudo do Comportamento do Solo-Cimento AutoAdensável. Revista Eletrônica de Engenharia Civil, v. 7, n. 2, p. 37-52, 2013.

CENTRE SCIENTIFIQUE ET TECHNIQUE DU BÂTIMENT. Note D'information Sur les Caractéristiques et le Comportement des Enduits Extérieurs D'imperméabilisation de Murs à Base de Liants Hidraulyques. Cahiers du CSTB, Paris, v. 230, n. 1778, juin 1982.

\section{CENTRO DE PESQUISAS E}

DESENVOLVIMENTO. Manual de Construção

Com Solo-Cimento. 3. ed. São Paulo: Ceped; BNH; Urbis; Conder; PMC; OEA; Cebrace; ABCP, 1984.

EDAMATSU, H.; NISHIDA, N.; OUCHI, M. A Rational Mix-Design Method for Self-Compacting Concrete Considering Interaction Between Coarse Aggregate and Mortar Particles. In: INTERNATIONAL RILEM SYMPOSIUM ON SELF-COMPACTING CONCRETE, 1 ., Stockolm, 1999. Anais... Stockolm, 1999. 
HARTMANN, C. T. Avaliação de Aditivos Superplastificantes Base Policarboxilatos Destinados a Concretos de Cimento Portland. São Paulo, 2002. 210 f. Dissertação (Mestrado em Engenharia) - Escola Politécnica, Universidade de São Paulo, São Paulo, 2002.

MILANI, A. P. S.; BARBOZA, C. S. Uso de Aditivo Plastificante em Solo-Cimento Plástico Para Fabricação de Paredes Monolíticas. In: ENCONTRO NACIONAL DE TECNOLOGIA DO AMBIENTE CONSTRUÍDO, 14., Juiz de Fora, 2012. Anais... Juiz de Fora: ANTAC, 2012.

MILANI, A. P. S.; LABAKI, L. C. Physical, Mechanical, and Performance of CementStabilized Rammed Earth-Rice Husk Ash Walls. Journal of Materials in Civil Enginnering, v. 24, n. 6, p. 775-83, 2008.

MIRANDA, L. F. R.; ÂNGULO, S. C.; CARELI, E. D. A Reciclagem de Resíduos de Construção e Demolição no Brasil: 1986-2008. Ambiente Construído, Porto Alegre, v. 9, n. 1, p. 57-71, jan./mar. 2009.
MISURELlIE, H.; MASSUDA, C. Como Construir Paredes de Concreto. Revista TÉCHNE, São Paulo, v. 147, p. 74-80, jun. 2009.

SEGANTINI, A. A. S. Utilização de SoloCimento Plástico em Estacas Escavadas Com Trado Mecânico em Ilha Solteira (SP). Campinas, 2000. 176 f. Tese (Doutorado em Engenharia Agrícola) - Faculdade de Engenharia Agrícola, Universidade Estadual de Campinas, Campinas, 2000.

TOKUDOME, S. Contribuição Para o Desenvolvimento do Concreto Auto-Adensável. Campinas, 2006. Dissertação (Mestre em Engenharia Civil) - Faculdade de Engenharia Civil, Arquitetura e Urbanismo, Universidade Estadual de Campinas, Campinas, 2006.

WONGTANAKITCHAROEN, T.; NAAMAN, A. F. Unrestrained Early Age Shrinkage of Concrete With Polypropylene, PVA, and Carbon Fibers. Materials and Structures, v. 40, n. 3, p. 289-300, 2007.

Ana Paula da Silva Milani

Faculdade de Engenharias, Arquitetura e Urbanismo e Geografia | Universidade Federal de Mato Grosso do Sul | Av. Costa e Silva, s/n, Bairro Universitario | Campo Grande - MS - Brasil | CEP 79070-900 | Tel.: (67) 3345-7478 | E-mail: ana.milani@ufms.br

\section{Christian Souza Barboza}

Faculdade de Engenharia | Universidade Federal da Grande Dourados | Cidade Universitaria | Caixa Postal 533 | Dourados - MS - Brasil | CEP 79804-970 | Tel.: (67) 3410-2171 | E-mail: christianbarboza@ufgd.edu.br

\section{Revista Ambiente Construído}

Associação Nacional de Tecnologia do Ambiente Construído

Av. Osvaldo Aranha, $99-3^{\circ}$ andar, Centro

Porto Alegre - RS - Brasil CEP 90035-190

Telefone: +55 (51) 3308-4084

Fax: +55 (51) 3308-4054

www.seer.ufrgs.br/ambienteconstruido

E-mail: ambienteconstruido@ufrgs.br 